\title{
Panem et circenses. El circo y las carreras de caballos
}

\author{
Gisela Ripoll Lopez *
}

Múltiples son los artículos y libros científicos que se han escrito sobre el mundo del circo romano y sus espectáculos. Había llegado el momento de hacer una reflexión conjunta sobre dicho tema. El director del Museo Arqueológico Henri Prades de Lattes (Montpellier), Christian Landes, tuvo la idea hace pocos años de hacer una serie de coloquios titulados Spectacula. En esta idea fue asistido por varias instituciones pero particularmente por el Centre Archéologique de l'Université de Toulouse-le-Mirail y por el Museo Saint Raymond de Tolosa, en la persona de Daniel Cazes. El primero de ellos fue celebrado en 1987 y trató el tema del anfiteatro y de los gladiadores, fruto del cual son un catálogo de la exposición ', las actas del congreso ${ }^{2}$ y un magnífico libro ${ }^{3}$. Estos volúmenes citados junto con la gran obra, que es en realidad la Tesis de Estado de Jean-Claude Golvin, L'amphithéatre ${ }^{4}$, cubren un campo que hasta ahora podía parecer olvidado por los investigadores de la arqueología clásica romana. A este auge del anfiteatro debemos sumar ahora las celebraciones que

* Departamento de Prehistoria e Historia Antigua, UNED. Madrid.

' LaNDES. Christian, edit. Les gladiateurs. Catálogo de la Exposición. Musee Archeologique de Lattes, Lattes, 1987, 191 págs., fotos color y blanco y negro.

Domergue. Claude; Landes, Christian, y Pailler. Jean-Marie. edit., Spectacula. I. Gladiateurs et amphitheatres, "Actas del coloquio Tolosa-Lattes, 1987". Lattes. 1990. 316 pags.

GOLvIN. Jean-Claude, y LANDES, Christian, Amphitheatres et gladiateurs. CNRS, Paris. 1990

Golvin, Jean-Claude. L'amphitheatre romain. essai sur la theorisation de sa forme et de sa fonction, 2 vols. Paris, 1988. Recordemos tambien aqui el libro sobre el mismo tema. aunque trata mucho menos los problemas arquitectonicos. sino los problemas históricos y del propio combate: VILLE, G., La gladiature en Occident. des origines a la mort de Domitien, BEFAR, 234, Roma. 1981. 
tendrán lugar en 1992 en Mérida, organizadas por el director del Museo Nacional de Arte Romano, José Maria Álvarez, con motivo del bimilenario del anfiteatro tan magnificamente conservado en la ciudad emeritense. Spectacula II, en 1989 estuvo dedicado al teatro: Le theâtre et ses spectacles ${ }^{5}$. Al igual que el precedente coloquio, éste estuvo acompañado de una exposición.

Por último, el coloquio celebrado los pasados 5,6 y 7 de octubre de 1990 sobre Le cirque et les courses de chars. Rome-Byzance viene a cubrir también un campo que hasta ahora era relativamente disperso. Por otra parte, las novedades tanto arqueológicas como históricas han requerido la reunión de numerosos especialistas para saber de dónde se viene y a dónde se va en el área de los estudios circenses. El coloquio, en el que participaron más de 150 congresistas y unos 25 comunicantes, estuvo acompañado de una excelente exposición con materiales procedentes de todas las provincias del imperio romano ${ }^{6}$.

Entre las piezas expuestas cabe destacar el famoso relieve de Foligno (Italia), cuya llegada a Lattes fue rocambolesca y algún dia Christian Landes tendrá que escribir su historia. El famoso relieve, presentando una carrera en el gran circo, es de un perfecto realismo, quizá la pieza arqueológica más precisa en este sentido, pues se observan todos los detalles de la arquitectura circense, desde el graderio, las carceres, la tribuna presidencial, las metas, el euripus - a veces impropiamente llamado spina-, además de todo el movimiento provocado por los personajes y las ocho cuádrigas de la arena, etcétera. El relieve de Foligno es, pues, uno de los ejemplos más relevantes del arte escultórico de finales del siglo II d.C. Otra famosa representación del Circus Maximus se pudo observar en la pasta vitrea imitando una amatista, procedente de Mont-Beauvray (Saône-et-Loire), conservada en el Museo Arqueológico de Dijon (Francia). Tambien una pieza expuesta de sumo interés era

'Las actas del coloquio no han sido todavia publicadas pero formarán el volumen Spectacula. II. Lo que si ha aparecido es el catálogo de la exposición, con una serie de articulos sobre el tema de bastante interes: LANDES, Christian, edit., Le goût du theâtre à Rome et en Gaule romaine. Catálogo de la Exposición. Musée Archéologique de Lattes, Lattes, 1989, 240 págs., fotos color y blanco y negro. Al mismo tiempo se publico un número monográfico: LANDES, Christian, et alii. "Les theatres de la Gaule romaine". Dossiers Histoire et Archeologie, número 134, Dijon, 1989, 88 págs.

${ }^{6} \mathrm{Ha}$ sido publicado ya el catálogo de la exposición que incluye una serie de articulos importantes sobre el tema del coloquio y sobre los materiales de la muestra. No mencionamos aqui los artículos que se incluyen pero si aconsejamos su consulta: LANDES, Christian. edit., Le cirque et les courses de chars. Rome-Byzance. Catalogo de la Exposición, Musée Archéologique de Lattes, Lattes, 1990, 391 págs.. fotos blanco y negro. 
Panem et circenses. El circo y las carreras de caballos

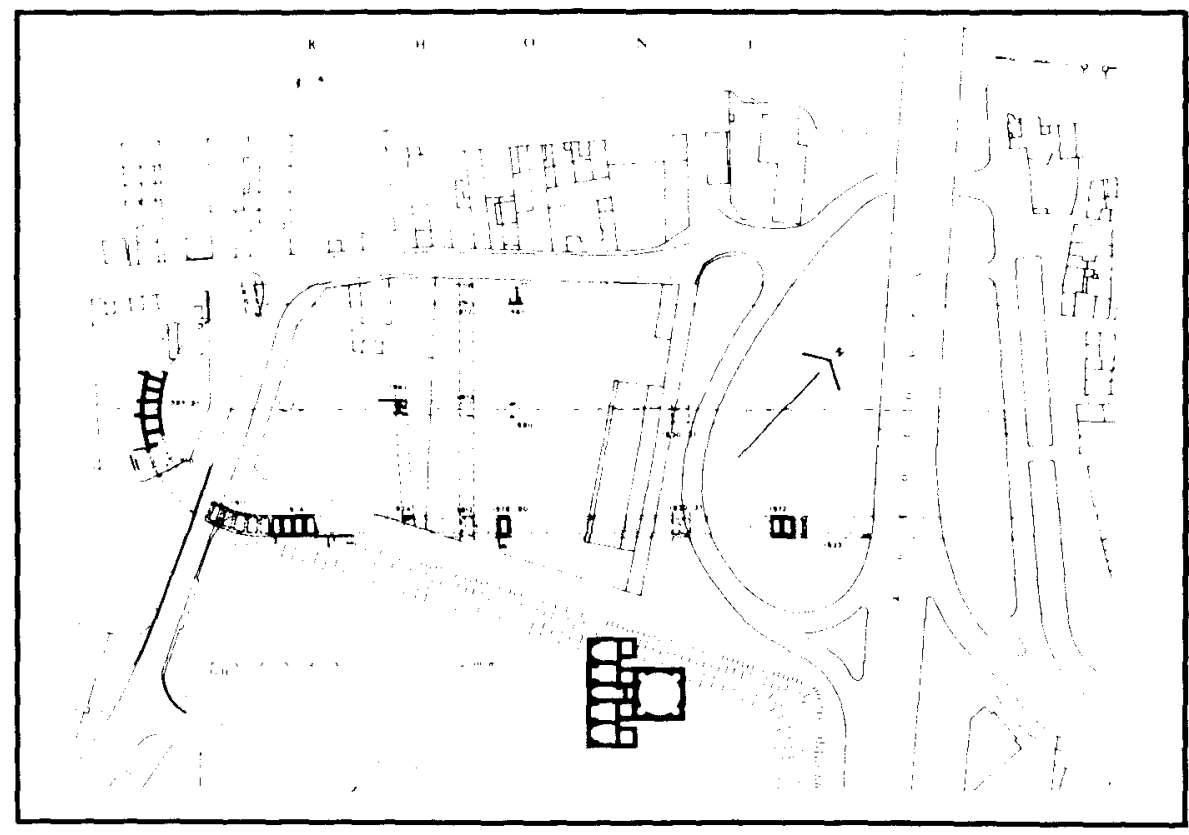

Fig. 1. Planta de circo de Arlés (según C. Sintès, et alii, 1990).

la tela bizantina con representación de una cuádriga conservada en el Museé National des Thermes et de l'Hôtel de Cluny (París), fabricada probablemente en un taller bizantino y fechado a finales del siglo vill d.C. o principios del siglo ix d.C. Cabe recalcar la muestra de los famosos cuchillos con cabezas de caballos y aurigas junto con sus respectivos nombres, conservados todos ellos en el "Cabinet des Médailles" de la Biblioteca Nacional de París. Otros relieves, cerámicas, inscripciones, planos, reproducciones fotográficas, etcétera, de esta exposición, permitieron a los congresistas trabajar con los materiales directamente y plantear desde un principio una serie de problemas a discutir en el coloquio.

La inaguración de las sesiones estuvo en manos de uno de los máximos especialistas en el circo romano, John $\mathrm{H}$. Humphrey (Some recent work on Roman circuses and chariot racing) ${ }^{7}$. Éste hizo referencia a los mayores problemas que se están planteando hoy en dia y a las noveda-

7 Humphrer, John H., Rornan circuses. Arenas for chariot racing, Berkeley-Los Angles, 1986. El profesor Humphrey está actualmente preparando un suplemento a esta edición con todas las novedades y que debe ser publicado en 1991. 


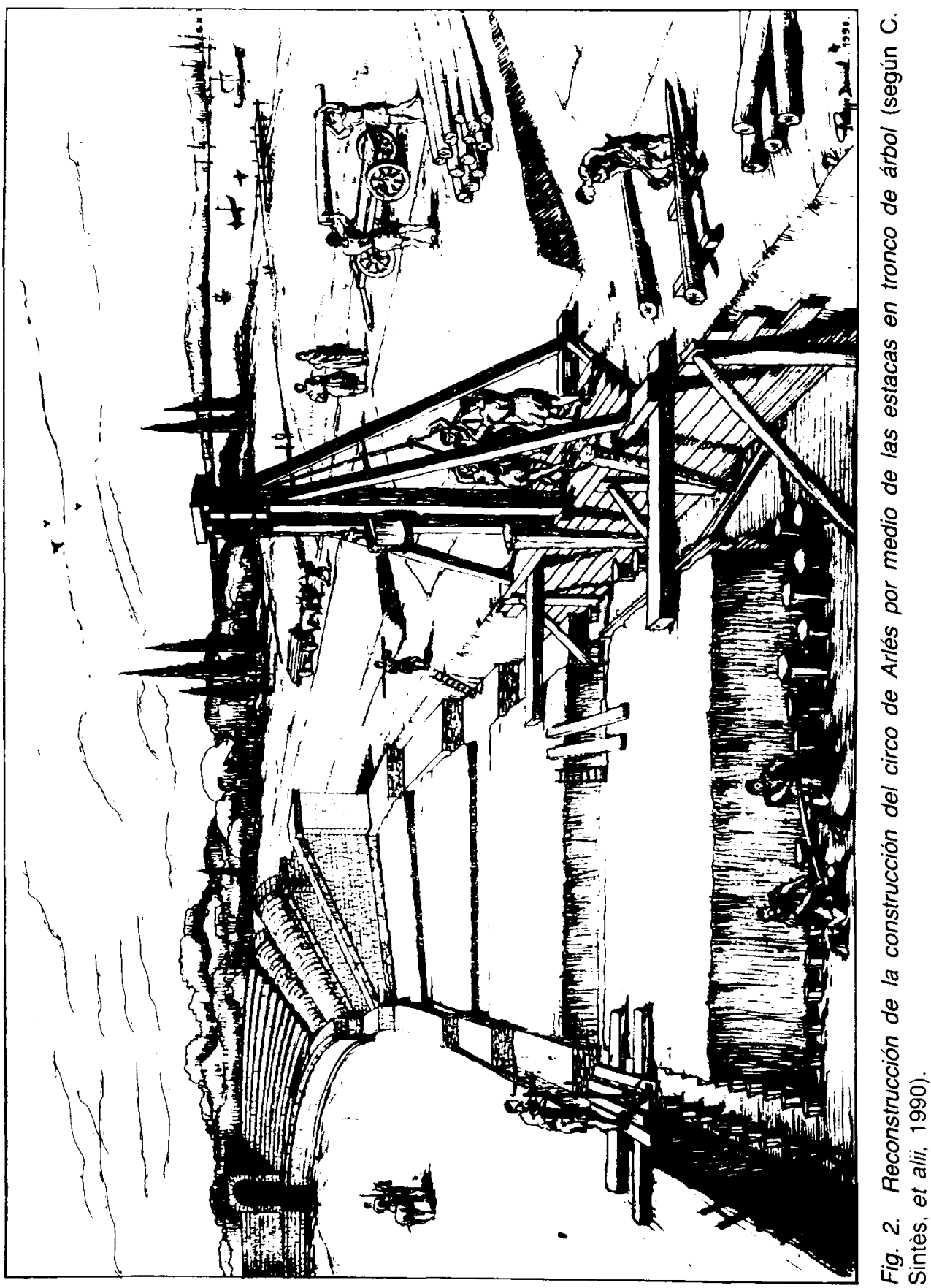




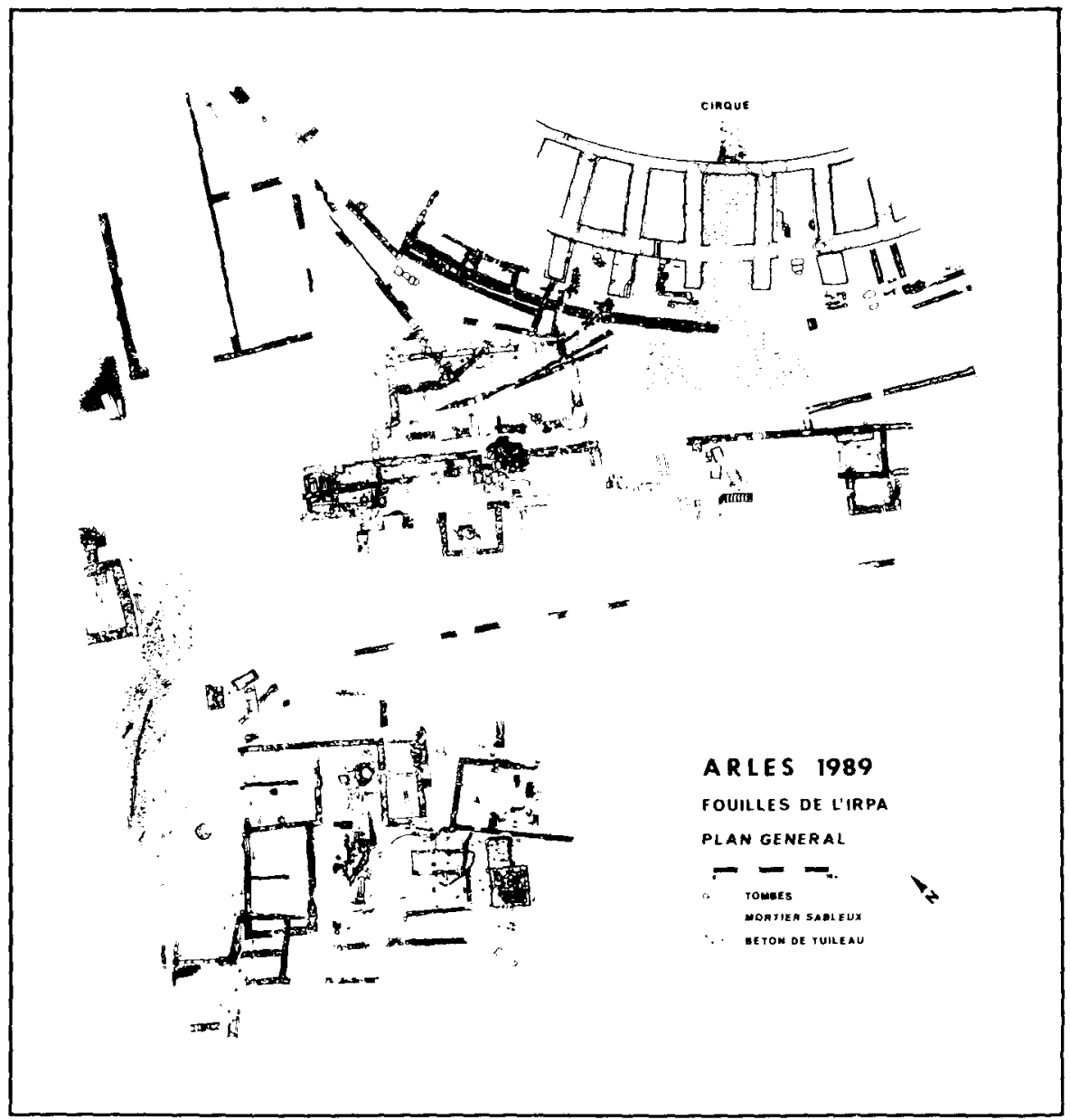

Fig. 3. Planta de las excavaciones de la cabecera del circo de Arlés, con las estructuras de la antigüedad tardia y de la necrópolis (según $\mathrm{C}$. Sintès, et alii, 1990).

des en el ámbito circense. Cabe resaltar en primer lugar las excavaciones que se están llevando a cabo en numerosos circos, como por ejemplo el de Arlés, excavado por un equipo dirigido por Claude Sintès que presentó unos resultados muy novedosos (Le cirque romain $d^{\prime}$ Arles) ${ }^{8}$. La construcción de dicho circo se hizo por medio de una serie

${ }^{8}$ Veáse a este respecto SInTES, Claude, et alii, "Carnets de fouilles d'une presqu'île". Revue d'Arles, 2, Arlés, 1990, 62 págs. 
de estacas de tronco de árbol hincadas en el suelo, sobre las cuales se apoya toda la estructura en piedra. Esto se hizo debido al terreno pantanoso que impedia el afianzamiento de la estructura pétrea directamente. Para su construcción se utilizaron alrededor de 25.000 o 30.000 troncos de árbol que corresponden a un bosque de unas 100 hectáreas. La estructura más antigua se ha podido fechar a finales del siglo I d.C., pero la más moderna, que comprende el ámbito de la pista, se sitúa a mediados del siglo ॥ d.C. Es muy posible que a pesar de que existen construcciones civiles adosadas en el exterior del edificio y que el entorno fuese un área funeraria se celebrasen carreras de carros en dicho circo hasta mediados del siglo vi.

Otros circos que están actualmente en proceso de excavación son los de Toledo ${ }^{9}$ y Mérida ${ }^{10}$. Las excavaciones muy recientes de Mérida, todavía en curso y dirigidas por F. J. Sánchez Palencia, han puesto al descubierto todas las carceres, completando asi la planimetría. También, gracias a una buena planimetria, se ha podido comprobar que se trata de los dos únicos circos - Toledo y Mérida - que responden a una misma y exacta estructura, hecho que no ocurre con los otros edificios circenses del imperio. Las excavaciones llevadas a cabo por el precedente equipo del TED'A en Tarragona ( $\mathrm{X}$. Aquilué, et alii, Le cirque de Tarragone. Etat des connaissances après les travaux réalisés de 1984 à 1990) ${ }^{11}$ son de suma importancia para conocer la relación del circo con el foro de dicha ciudad, pero esta investigación se ha visto truncada al serles retirada la propiedad intelectual de los trabajos realizados a todo el equipo dirigido por Xavier Dupré. Por otra parte, los circos de Toledo, Mérida y Tarragona son contemporáneos, es decir, del siglo I d.C., lo cual demuestra la gran afición de este tipo de espectáculos en la diocesis hispaniarum desde una época muy temprana, frente a una más tardía en el Norte de África, donde parece que ésta se inicia hacia el siglo II. Todo ello viene demostrado por las excavaciones dirigidas por el propio John

9 Sanchez Palencia, F. J., et alii, "Estratigrafia y arquitectura del circo romano de Toledo", I Congreso de Historia de Castilla-La Mancha. I. IV: Romanos y visigodos: hegemonia cultural y cambios sociales. Toledo, 1988, págs. 225-236, 7 figs. Ídem, El circo romano de Toledo: estratigrafia y arquitectura. Museo de Santa Cruz., Estudios y monografías, 4, Toledo, 1988, 46 págs., 23 figs.

${ }^{10}$ Es obvio que los resultados de la excavación de Mérida no han sido publicados pues ésta está todavia en curso.

1 DUPRE, Xavier, et alii. El circ romà de Tarragona. I. Les voltes de Sant Ermenegild, Departamento de Cultura de la Generalitat de Cataluña, Barcelona, 1988. El segundo volumen del TED'A se espera aparezca en un futuro muy próximo. Para las conexiones del circo con el foro: TED'A, “El foro provincial de Tarraco, un complejo arquitectónico de época flavia", Archivo Español de Arqueologia, 62, 1989, págs. 141-191. 


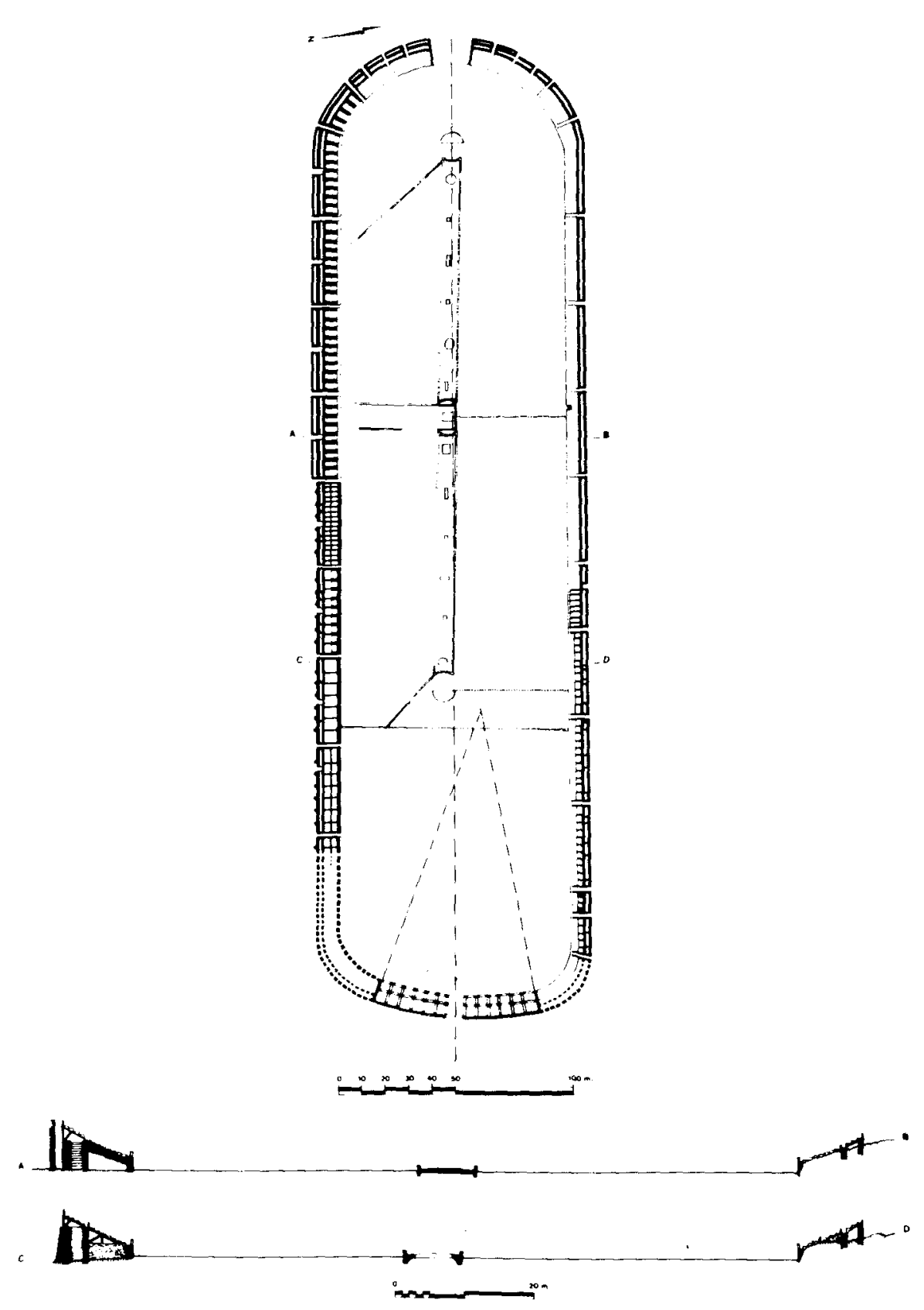

Fig. 4. Planta y sección del circo romano de Toledo (según F. J. SánchezPalencia, et alii, 1988). 

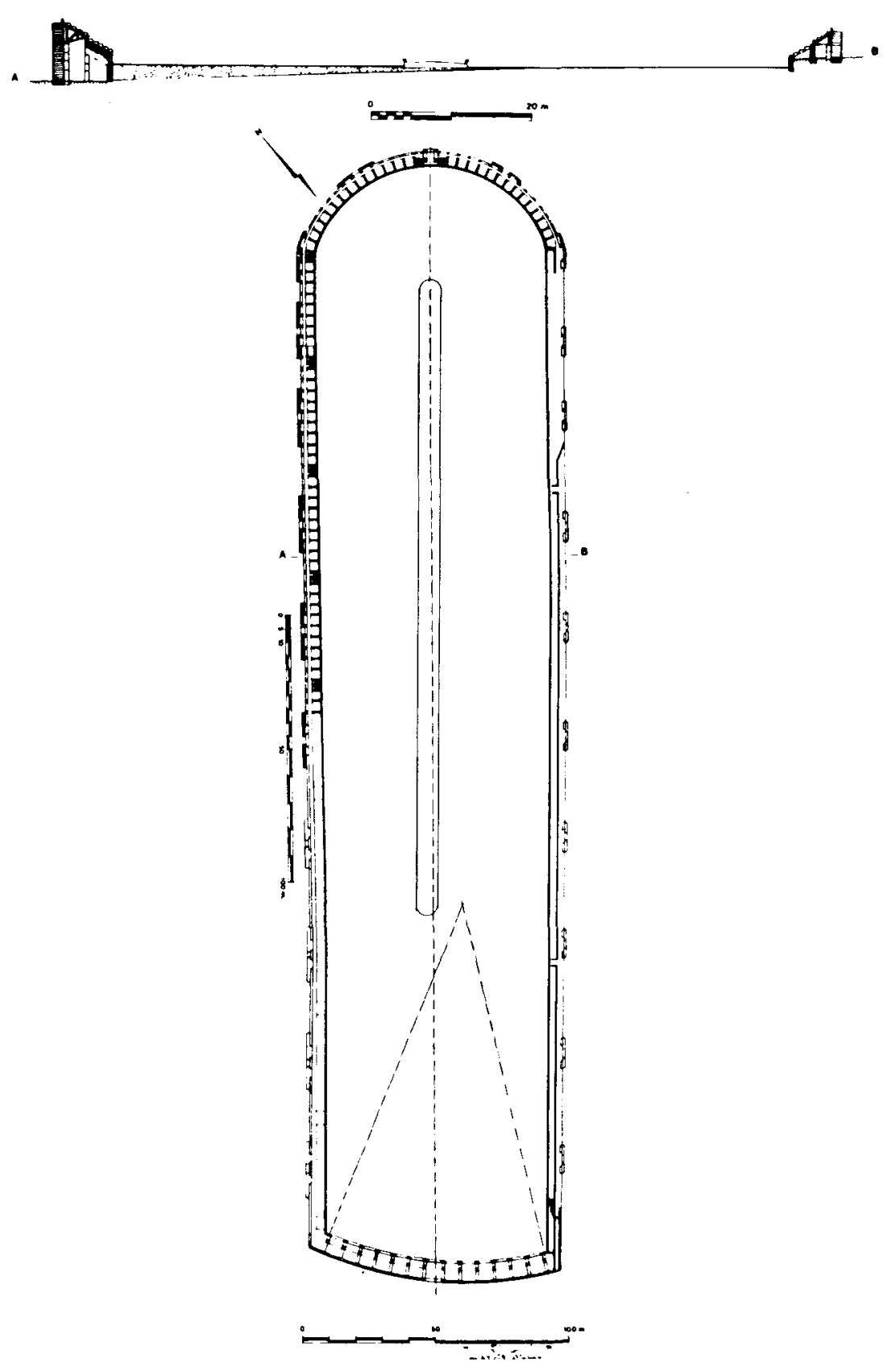

Fig. 5. Planta y secciones del circo romano de Mérida (según F. J. SánchezPalencia, et alii, 1988). 
H. Humphrey y Noami Norman, de las Universidades de Michigan y Georgia, respectivamente ${ }^{12}$. También esta afición tardía en el Norte de África viene atestiguada gracias a la gran cantidad de restos musivos con iconografía equina ${ }^{13}$ y al gran número de defixionum tabellae que fueron estudiadas en su dia por Audollent ${ }^{14}$, y que como dijo Marta Darder en su comunicación (Los nombres de caballos circenses: fuente documental para el estudio de los espectáculos de circo) todas las cronologías de estas defixiones deben ser revisadas. Respecto a esta comunicación tratando los nombres de caballos, es éste un tema que se está estudiando de nuevo ${ }^{15}$, puesto que la clasificación realizada por J.W. Salomonson ${ }^{16}$ con aproximadamente 150 nombres de caballos no tenía en cuenta una clasificación semántica realizada desde la óptica de la filologia. El trabajo de M. Darder cuenta con 1.000 nombres de caballos de los cuales existen 600 variantes, sólo en la pars occidentis, sobre diversos materiales tanto inscripciones, mosaicos, contorniatos, cuchillos, sarcófagos, defixiones, etcétera. Cada vez son más abundantes los hallazgos musivos con nombres de caballos; asi, por ejemplo, el mosaico hallado en la calle Holguín, recientemente instalado en el Museo de Mérida ${ }^{17}$, el de la villa romana de Aguilafuente (Segovia) ${ }^{18}$, o el del llamado "Palazzo Imperiale» de Ostia Antica. La mayoria de testimonios corresponden a epocas tardías como finales del siglo III hasta el siglo $v$, lo cual indica una gran afición en todo el imperio durante este período, que corresponde también en muchos casos a restauraciones de circos; asi, por ejemplo, el caso

12 Humphrey, J. H.. edit. The Circus and a Byzantine Cemetery at Carthage, The University of Michigan Press, Ann Arbor, 1988.

13 ENNAIFER, Mongi, "Le theme des chevaux vainqueurs à travers la série des mosaïques africaines". Mélanges de l'Ecole Française de Roma-Antiquité, 95, 1983, págs. 817 858, 31 figs. Puede verse también la tesis doctoral dactilografiada y nunca publicada de YaCOUB. M., Recherches sur les mosaiques tunisiennes relatives au monde du cirque. Paris, 1979. Confrontar también Dunbabin. K. M. D., The Mosaics of Roman North Africa, Oxford, 1978. Idem, "The victorious charioteer on Mosaics and related monuments", American Journal of Archeology, 86, 1982, págs. 65-89.

${ }^{14}$ Audollent, A., Defixionum tabellae..., Paris, 1903.

15 Darder, Marta. "Els noms de cavalls i d'auriges al mosaic de la Torre de Bell-lloc (Girona): paral. Jels a l'imperi romà", Fonaments, 1988 (en prensa). Dicha investigadora esta acabando su tesis doctoral sobre los nombres de caballos circenses, que será leída en la Universidad Autónoma de Barcelona, bajo la dirección del profesor Marcos Mayer

${ }^{16}$ Salomonson, J. W. Mosaique aux chevaux de l'antiquarium de Carthage. La Haya, 1965, págs. 80-92.

17 Álvarez Martinez, José María, Mosaicos romanos de Merida. Nuevos hallazgos, Monogratias Emeritenses, 4, Mérida, 1990, págs. 79-91, láms. 39-45.

18 LUCAS PELLICER, M. R. "La influencia africana en la iconografia equina de la villa de Aguilafuente (Segovia)", Cuadernos de Prehistoria y Arqueologia, 13-14, Homenaje al profesor Gratiniano Nieto, Universidad Autónoma de Madrid, Madrid, 1986-87, vol. 11, páginas 219-235, 6 figs. y 2 láms. 


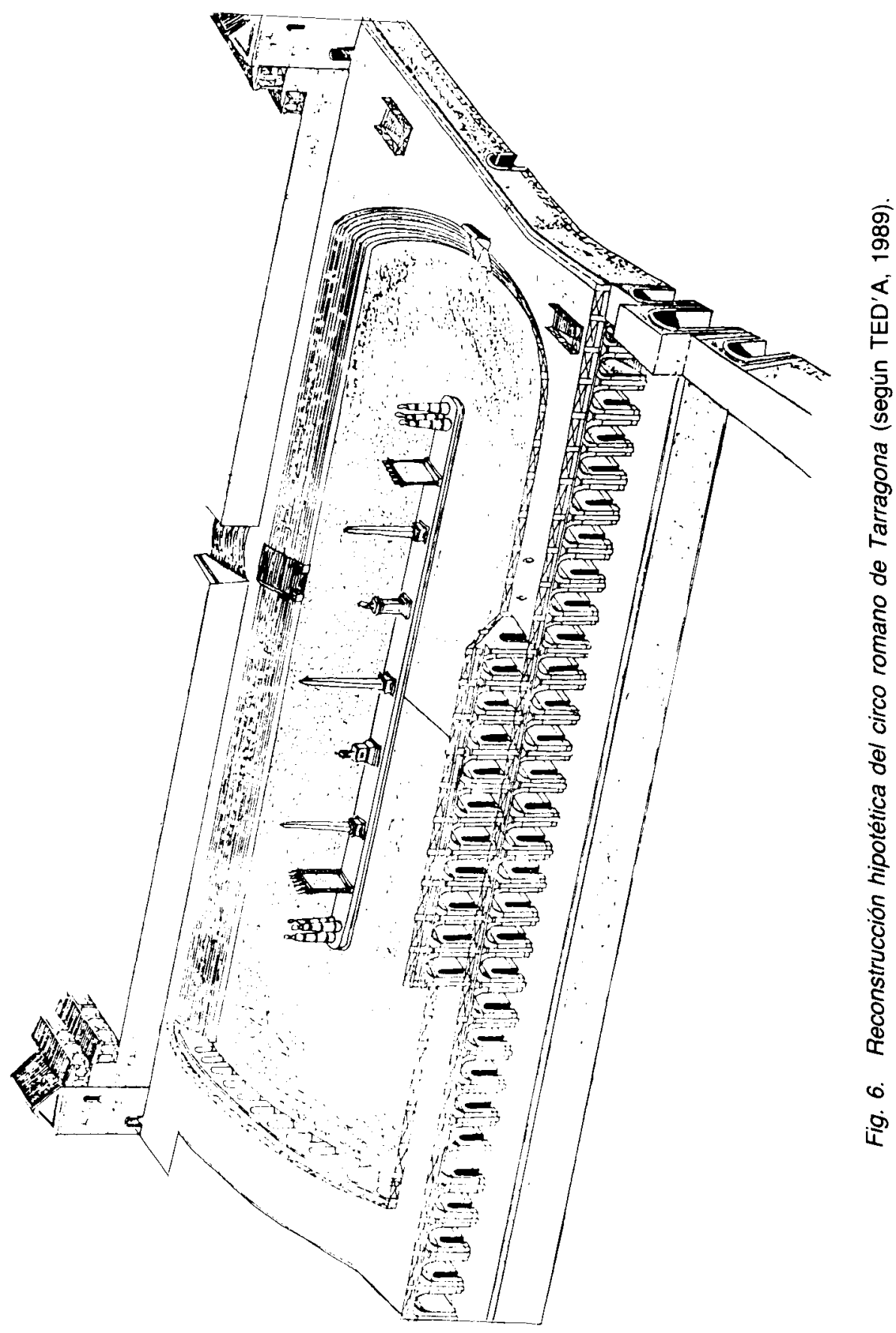


del circo de Mérida donde se halló una inscripción alegando este hecho ${ }^{19}$.

Otros circos que están siendo nuevamente documentados a través de la excavación es, por ejemplo, el caso del de Miróbriga, en Portugal ${ }^{20}$, fechado hacia el siglo IV. Todavía subsiste la duda en saber si se trata de un circo destinado únicamente a entrenos o si éste incluía también representaciones. Otro circo que cabe mencionar es el de Gerasa (Jordania) ${ }^{21}$, cuya construcción se sitúa hacia los años 150-170 d.C. aunque es posible que éste no fuese utilizado hasta una época más avanzada. En Roma, tanto los circos de Majencio como el circo Máximo, están siendo objeto de nuevos estudios en manos de Giuseppina Pisani Sartorio, para el primero, y Paola Ciancio Possetto, para el segundo. Estas investigaciones se ven apoyadas por una de carácter diferente, pero no por ello de menor interés, que es la de la tipología monumental en el renacimiento llevada a cabo por Silvia Tomasi Velli (Les antiquaires et le cirque romain. Redécouverte d'une typologie monumentale à la Renaissance). En esta comunicación se ha analizado con detenimiento y particularmente el tratado de Pirro Ligorio: Libro delle Antichita di Roma, nel quale si tratta de'Circhi, Teatri e Anfithetri (1553). En este sentido la comunicación de esta autora puso de relieve el espiritu fantasioso - a veces- de estos autores que causaron distorsiones y graves errores en el momento de estudiar los restos circenses. Podriamos traer a colación el ejemplo, aunque más tardio del siglo XVIII, de L'Encyclopédie de Diderot y Alembert ${ }^{22}$. Cabe citar también las idealizaciones que se han hecho siempre sobre la spina y euripus. La comunicación de Jean Claude Golvin (Les obélisques de la spina) ${ }^{23}$ fue muy ilustrativa pues relató cómo fueron transportados los obeliscos del templo egipcio de Amon-Rê de

19 Chastagnol, Andre, "Les inscriptions constantiniennes du cirque de Mérida", Melanges de l'Ecole Française de Rome-Antiquité. 88, 1976, págs. 259-276. Algunos de estos problemas mencionados los esbozamos ya en: DARDER, Marta, y RIPOLL, Gisela, "Caballos en la antigüedad tardía hispánica», Revista de Arqueología, 104, Madrid, 1989, págs. 40-51.

20 BiERs Williams, R., Mirobriga. Investigations at an Iron Age and Roman Site In Southern Portugal by the University of Missouri-Columbia, 1981-1986, "British Archaeological Repports", S451. Oxford, 1988. Véase particularmente la contribución de K. W. Slane en las págs. $31-47$

21 Varios articulos sobre el hipódromo de Gerasa en: Jerash Archeological Project 1984-1988, publicación fuera de serie num. 18, Syria, 66, Paris, 1989.

${ }^{22}$ L'Encyclopedie de Diderot y Alembert. Véase: Recueil de planches sur les sciences, les arts libéraux et les arts méchaniques, avec leur explication. Paris, 1766 (?), lám. IV (utilizamos un reprint sin techa ni lugar de edición bajo el epigrafe: Antiquités).

${ }^{23}$ Golvin, Jean-Claude, "Quelques travaux récents du Centre Franco-Egyptien de Karnak. 1985-1988". Comptes rendus de /'Académie des Inscriptions et Belles-Lettres, Paris, 1988 , págs. $575-599,7$ figs. 


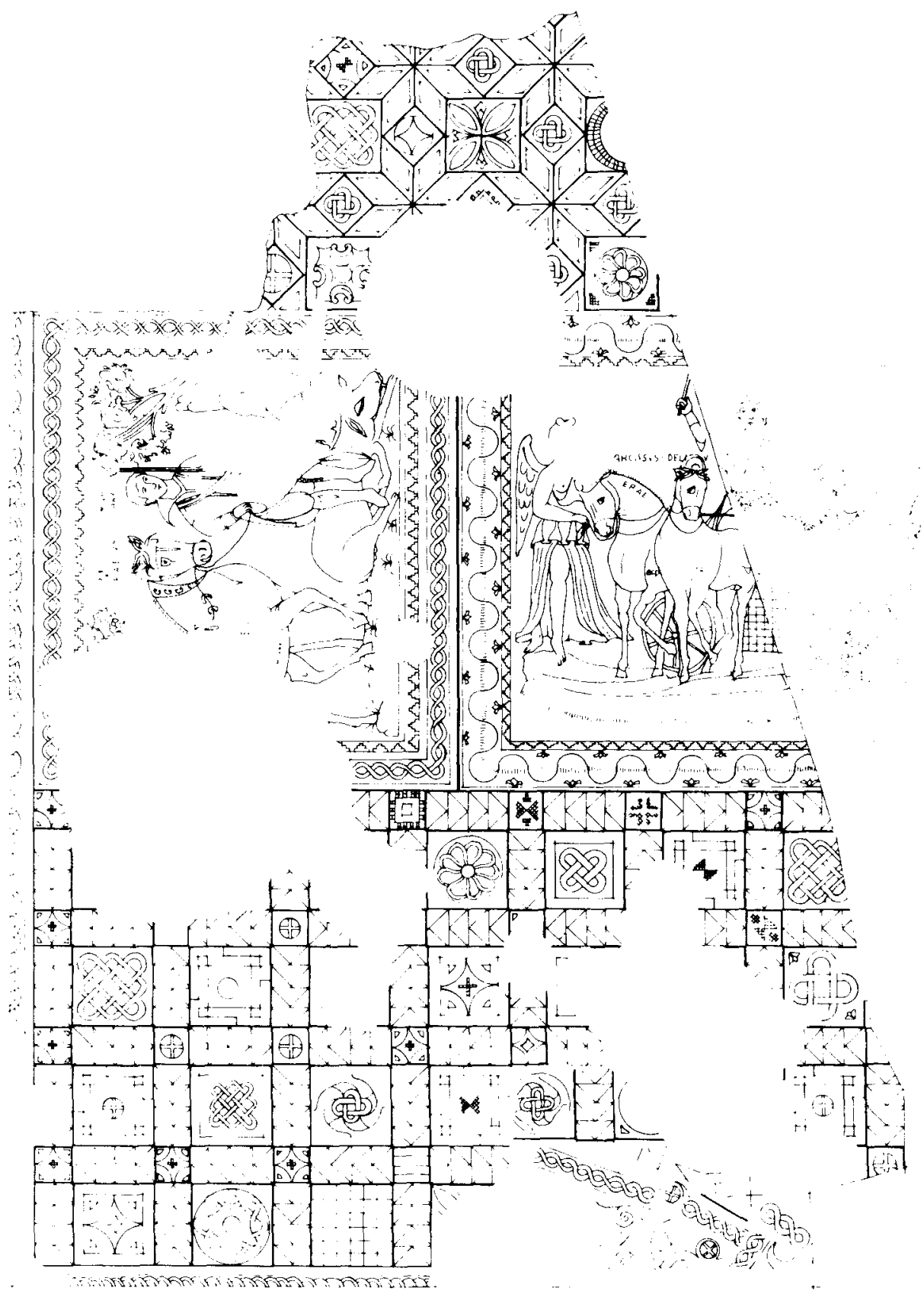

Fig. 7. Dibujo del mosaico de la calle Holguín, de Mérida (según J. M. Álvarez, 1990). 
Karnak, hasta el Circus Maximus ${ }^{24}$ de Roma y el de Constantinopla, y cómo fueron de nuevo levantados, ayudándose para ello de las ilustraciones realizadas por D. Fontana en 1590 (Della trasportazione dell'obelisco vaticano et delle fabbriche di nostro Signore Papa Sisto V.

Entre las comunicaciones que permitieron adentrarse en el campo de la arquitectura circense debemos citar también la de Françoise Dumasy sobre la pintura (Scènes de course de chars dans la peinture gallo-romaine) con comentarios posteriores hechos por la especialista en el tema: Alix Barbet, y la de Hélène Guiraud (Images du cirque sur les gemmes). Las gemas hasta ahora poco estudiadas ${ }^{25}$ pueden ser una fuente documental muy valiosa pues en ellas se encuentran diferentes tipos de representaciones del circo, tomando casi siempre como modelo el circo máximo, como decíamos al principio al comentar la escena de la pasta vítrea de Mont-Beauvray. Por regla general la mayoría de ellas se pueden fechar hacia el año 200 , fecha que viene a ponerse en relación con la explosión de la afición por los ludi circenses, aunque es muy posible que muchas de ellas tengan una fecha más tardía pues aparecen representados los modii - y no altares - característicos de la antigüedad tardía como veremos al comentar la comunicación de Noël Duval. También debemos citar la importancia que tienen otros tipos de objetos como los vidrios o cuencos ${ }^{26}$, los contorniatos ${ }^{27}$, o los ostraca ${ }^{28}$, para el estudio del circo y las carreras de carros.

Como vemos todas las comunicaciones hasta aqui reseñadas hablan sobre el espacio físico del circo, pero la segunda sección hizo referencia a los hombres y animales que hacian posible, en definitiva, estos espec-

${ }^{24}$ D'Onofrio, C., Gli obelischi di Roma, Ivi, 1966. Rossi, G. B. de. Nuova raccolta degli obelischi et colonne antiche dellalma città di Roma, sin fecha ni lugar de edición.

${ }^{25}$ Aunque existen muchos catálogos de museos donde se reunen las gemas, poca es la atención que han merecido las que llevan escenas circenses. Véase, por ejemplo, MaAS. KANT-KLEIBRINK, M., Catalogue of the Engraved Gems in the Coin Cabinet. The Greek. Etruscan and Roman Collections, La Haya, 1978, con bibliografia sobre el tema.

26 Véase de publicación reciente: DARDER, G-Z-LisSon, Marta, "Noms d'aurigues i de gladiadors en dos peces de vidre d'Empúries", Espacio, Tiempo y Forma, Homenaje al profesor Eduardo Ripoll Perelló. serie Il. Historia Antigua, tomo I, Madrid, 1988, págs. 287. 300,7 figs. En este artículo se reúne la bibliografia más reciente sobre vidrios con escenas de circo y antiteatro.

Al.FOLDI, A., Die Kontorniaten. Ein verkanntes Propagandamittel der Stadtrömischen heidnischen Aristokratie in inhrem Kämpfe gegen das christliche Kaisertum, Budapest-Leipzig, 1942-43. Elisabeth Alföldi Rosenbaum ha publicado muy recientemente en el Instituto Arqueológico Alemán de Berlin un nuevo volumen sobre este tipo de piezas, con diferentes colaboraciones de otros investigadores

${ }^{28}$ SHELTON, John C., Greek ostraca in the Ashmolean Museum from Oxyrhynchus and other sites (O. Ashmolean Shelton), Papyrologica Florentina, XVII, Florencia, 1988. 
táculos. Debemos tener en cuenta que la celebración de este tipo de manifestaciones requeria una organización muy peculiar: desde la selección de los caballos hasta las carreras y espectáculos que se desarrollaban en la arena del circo. Véase por ejemplo la comunicación de Gian Luca Gregori y Patrizia Sabbatini Tumolesi (Testimonianze di spettacoli "anfiteatrali" nel circo) ${ }^{29}$. Para conocer el funcionamiento de un espectáculo de este tipo es necesario profundizar en las primeras influencias recibidas, y de ello se ocupó Jean-Paul Thuiller (Les influences étrusques sur le cirque romain). Estas influencias etruscas son evidentes y además importantes, tal como lo ponen de relieve los textos literarios así como los documentos iconográficos. Estos últimos procedentes en su mayoría de la necrópolis de Tarquinia, ilustran tras un análisis minucioso, el papel que jugó esta cultura sobre las primeras manifestaciones circenses romanas ${ }^{30}$.

La comunicación de Jean-Charles Balty (Portrait et société: bustes et statues d'auriges vainqueurs), trató pues el tema de las representaciones de los aurigas vencedores incidiendo de nuevo en lo que se llama "hipomanía". El recorrido que hizo dicho investigador a través de los antiguos y nuevos hallazgos escultóricos, puso de relieve que este tipo de materiales puede llevar a conocer no sólo la importancia del auriga dentro de la sociedad sino también el poder profundizar en el campo de la indumentaria circense y toda la pompa ludicra de la que se acompañaban estos espectáculos. Sobre los aspectos del ludismo, Florence Dupont (Le ludisme romain. Etude de la procession du cirque) aportó una serie de consideraciones muy particulares que replantean de nuevo la forma de estudiar los aspectos lúdicos o no lúdicos de estos juegos. Este hecho no puede ser disociado de la Historia Augustea, aunque se debe tener en cuenta que este texto relata unos acontecimientos ocurridos con anterioridad a su relato que es del siglo IV. Yves de Kisch (Les empereurs et le cirque d'aprés l'Histoire Auguste) hizo un repaso sobre la documentación de este texto y demostró el intervencionismo estatal en la organización de dichos espectáculos ${ }^{31}$, tema que por otra parte no fue muy tratado a lo largo de las comunicaciones y discusiones del coloquio, y sobre el cual probablemente se tenía que haber incidido más.

${ }^{29}$ Se trata en realidad de un resumen de los autores del reciente libro que acaba de ser publicado sobre este mismo tema.

30 THuILlER, J.-P., Les jeux athlétiques dans la civilisation étrusque, Roma (BEFAR, 256), 1985.

31 VEYNE, Paul, Le pain et le cirque. Sociologie historique d'un pluralisme politique, París, 1976, pág. 799. 
Éstas, entre otras, fueron las comunicaciones leídas en el coloquio de Lattes, pero citaremos por último la comunicación de Noël Duval sobre las coronas agonísticas y los premios (Les prix du cirque dans l'Antiquité tardive) ${ }^{32}$. A través del estudio llevado a cabo por N. Duval se ha podido llegar a cernir mejor la iconografía de los premios, es decir, la corona y la palma para los aurigas, tratándose de una corona agonística metálica y ligera, con una decoración epigráfica y probablemente gemada. Los premios que recibían los caballos, que al fin y al cabo eran los que tenían el papel principal en las carreras, son representados por un modius, que en un principio estuvo lleno de alfalfa y que luego se llenó de aureii. Este modius iconográficamente está muy cerca de la representación de la corona, pues es dorado y con gemas, y con palmas simbólicas. El problema se plantea en el momento de saber a quién iba destinado el premio otorgado al caballo y toda la suma de dinero que éste contenía. Este problema - el de la financiación de los juegos- fue poco tratado a lo largo del coloquio, queda pues para estudios venideros, al igual que la importancia de estos juegos en la antigüedad tardia. pues se tienen numerosos testimonios del desarrollo de éstos no sólo en la pars orientis donde es un fenómeno normal, sino también en la pars occidentis. También se dió poca importancia al caballo en sí mismo ${ }^{33}$, a excepción de la ya citada comunicación de $M$. Darder, donde el análisis de los nombres se hizo a través de la vida de un caballo desde su aparición en la cuadra hasta su llegada al circo, y la de Franck Boudry (Les chevaux des courses de chars à Rome) que aunque no fue leída, sí formará parte de las actas. Sabemos de la importancia de esta comunicación y de su contenido que atañe directamente al adiestramiento y entreno de los caballos que tomaban parte en las carreras de circo.

A lo largo de estas cortas páginas hemos visto, pues, que los tres dias transcurridos en Lattes fueron densos y provechosos, abriendo nuevos temas en la investigación de los ludi circenses, como, por ejemplo, la construcción y utilización de los circos privados, el complejo sistema de la financiación, la importancia de la superstición y lo que ello implica con respecto a la sociedad, algo tan simple pero difícil de saber como es el precio de las localidades, la economía intrínseca de estos espectáculos, la estrecha relación de los juegos circenses con el poder imperial y

32 Duval, N., "Nouvelles considérations sur les prix de concours dans l'iconographie du Bas-Empire", Bulletin de la Société Nationale des Antiquaires de France, 1983, págs. 190200. Con bibliografia anterior.

33 Hyland, Ann, Equus: the Horse in the Roman World, Yale University Press, New Haven y Londres, 1990,285 páginas. 
el poder político, el paso - por el momento tan desconocido- de los espectáculos entre el alto y bajo imperio, todos los aspectos en contra de estos juegos hechos por los padres de la iglesia, la perduración de las carreras -como decíamos anteriormente en la antigüedad tardía, asi como las principales innovaciones acontecidas a finales del siglo $\mathrm{I}$, etcétera. Pero para responder a todos estos problemas está el futuro de la investigación y básicamente Christian Landes, magnífico anfitrión, y su eficiente equipo, para organizar un segundo coloquio sobre el circo romano, en un futuro que esperemos no sea muy lejano. 